\title{
Steel-concrete composite plates with flexible shear connectors
}

\author{
J. L. CLARKE \& C. T. MORLEY
}

Mr K. R. Moffatt, Imperial College of Science and Technology, and Dr P. T. K. Lim, Constructional Steel Research and Development Organisation

We are at present applying the finite element method to a study of the partial interaction phenomenon in composite structures. For the purpose of the investigation, several eccentric beam elements, eccentric plate elements and linkage elements have been incorporated within an existing general purpose finite element program. ${ }^{9}$ By virtue of the generality of the finite element method, the same program can be used to study such effects as slip and separation in composite beams, plates and box girders. However, such generality inevitably results in considerable computer costs and the Authors are to be complimented on developing a relatively more efficient method for studying the effect of slip in composite plates.

27. The finite element program was used to analyse the square composite plate model described in the Paper. Owing to double symmetry only one quarter of the plate was analysed with the idealization shown in Fig. 9. The structure was represented by two layers of eccentric plate elements connected to each other at the

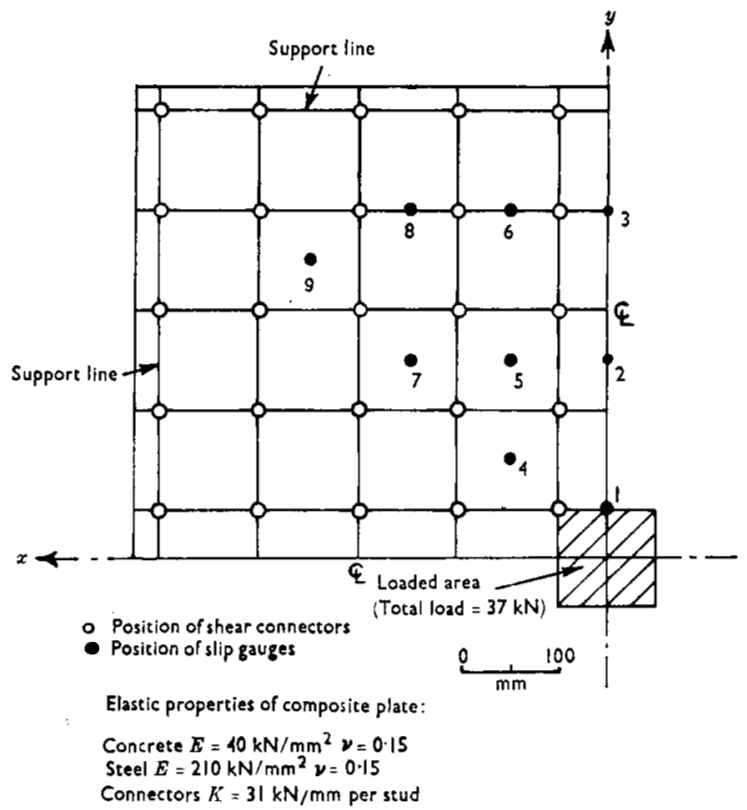

Fig. 9. Finite element idealization of square composite plate

Paper published: Proc. Instn Civ. Engrs, Part 2, 1972, 53, Dec., 557-568. 


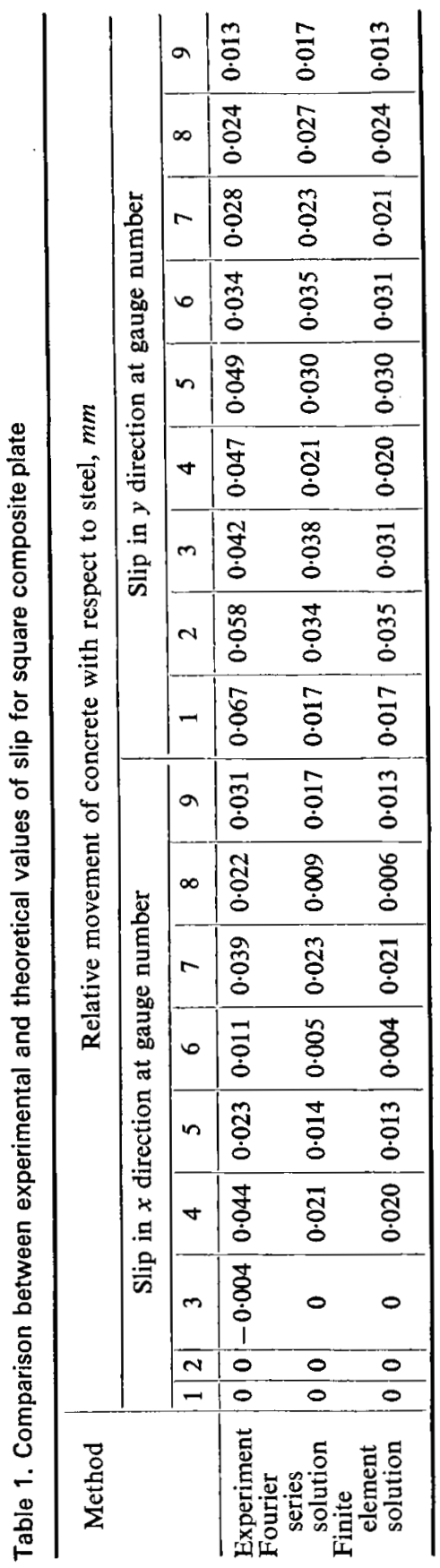


nodes by means of linkage elements. The nodes were each assumed to lie in the plane of the concrete-steel interface and to have five degrees of freedom $(u, v$, $w, \theta_{x}$ and $\theta_{y}$ ). (Not all the degrees of freedom are independent in this case and so the program reduces the number of stiffness equations before the solution process.) The values of elastic properties used in the analysis corresponded to those used by the Authors. ${ }^{10}$ In particular it should be noted that the Poisson's ratio of the steel has been assumed to be equal to that of the concrete.

28. The values of slip obtained from the finite element analysis are compared with the Authors' experimental and theoretical results in Table 1. It can be seen that the two sets of theoretical results are in close agreement. However, the agreement between the experimental and theoretical results is only reasonable, indicating that the assumption of linear behaviour on which both analyses are based may not be strictly valid for this particular model test.

29. In developing their theory for rectangular composite plates the Authors have assumed that the two composite materials have the same Poisson's ratio. This assumption is perhaps an unnecessary restriction although, in general, it is unlikely to be of any practical significance. In the case of the plate under consideration, finite element analyses indicate that a change in the Poisson's ratio of the steel from $0 \cdot 15$ to 0.30 results in a change of less than $3 \%$ in the maximum slip value.

30. The computer cost of a finite element analysis which allows for partial interaction is generally considerable, and so this aspect of the program is of limited practical value. Nevertheless, the program is suitable for use as a research tool and at present is being used to determine the effect of shear connector spacing on the behaviour of composite box girder bridges.

\section{Dr Clarke and Dr Morley}

The finite element, partial interaction analysis developed by $\mathrm{Mr}$ Moffatt and Dr Lim will be very useful for studying the effect of slip in complex structures. The more elementary methods presented in the Paper can deal only with relatively simple problems, but they do allow a large number of loading cases to be analysed cheaply, so that the effect of altering various geometrical or stiffness parameters can be studied easily, and plots of stresses due to moving loads can be obtained, with moderate expenditure on computation. It is interesting that the two methods of analysis give similar results for the model square composite plate.

\section{References}

9. Lim P. T. K. and Moffatt K. R. General purpose finite element program. Proceedings of the Symposium on Bridge Program Review. P.T.R.C., London, 1970.

10. Morley C. T. Private communication. 